\title{
THE SOCIAL MARKETING STRATEGY AND TRANSPORT POLICY TO IMPROVING THE QUALITY OF LIFE IN URBAN AREA
}

DOI: http://dx.doi.org/10.18509/GBP.2019.31

UDC: 339.138:656.11(497.7)

\author{
Riste Temjanovski \\ University "Goce Delcev"- Stip, Faculty of Economics, North Macedonia
}

\begin{abstract}
This paper sheds light of alarming condition of transport emission pollution devastated our environment. In this real condition which is position of social marketing philosophy, identify like some global trend in using for public health or cry for save our living environment.

The strong growth in the development of traffic, especially in fast, safe and flowing transport, besides the huge benefits, has certain negative consequences of environment. In this regard, in relation to the current traffic model with the current transport activities, there is a certain consensus among the states regarding the sustainable development of the environment, both locally and globally. But how to be operative and effective to limit these negative impacts of automobile use.

There are many opportunities to improve the efficiency and reduce the environmental impact of local, national and international road transport. The mostly governmental bodies and transportation agencies employ a number of different strategies including changes in transportation policy, infrastructure, and technology.

This paper also points out the investigation how to develop marketing campaigns that will encourage people to voluntarily switch to alternative modes of transportation such as walking, biking, or using public transit. Social marketing can be seen as an instrument to reduce using of private traffic car and stimulate public transport. The field of Social Marketing provides valuable insight into how stimulate public opinion through marketing and promotional strategies can be used more generally to encourage the adoption of behavior changes that benefit health, the environment, and the social condition.
\end{abstract}

Keywords: social marketing, greenhouse gas emissions, transport policy, urban area, environment

\section{INTRODUCTION}

Study of transport, as a factor of economic efficiency, requires a full approach, since it is only on this basis that the contribution of traffic in efficient management can be properly assessed. The traffic is treated as a complex economic, technical-technological and organizational system, but also as a subsystem of the economic and social system. Therefore, the efficiency of traffic is also a general condition for the development of every society and economy, its efficiency is not only economically important, but on the contrary it also encompasses a wider social significance.

Transport infrastructure is crucial for economic development, as transport services are essential for reaching world markets, strengthening global integration, vital for the economic and social cohesion of regional development and attracting foreign investment. But, implementation of better transport infrastructure would increase further the overall rate of growth of passenger and freight transport. 
The emissions from road traffic affect the air pollution the most from the transport sector. The impact of road traffic emissions is the highest in urban areas with dense road networks and high volume of vehicles. The road traffic contributes to the nitrogen oxides, carbon monoxide, benzene and particulate, heavy metal and polycyclic aromatic hydrocarbon emissions. The emissions from road traffic depend on the type and age of the vehicles, mileage of each vehicle group and quality of the fuels used in the vehicles. Passenger vehicles are a major pollution contributor, producing significant amounts of nitrogen oxides, carbon monoxide, and other pollution. In 2013, transportation contributed more than half of the carbon monoxide and nitrogen oxides, and almost a quarter of the hydrocarbons emitted into our air.

According the World Health Organization [1] air pollution levels remain dangerously high in many parts of the world. New data shows that 9 out of 10 people breathe air containing high levels of pollutants. WHO estimates that around 7 million people die every year from exposure to fine particles in polluted air that penetrate deep into the lungs and cardiovascular system, causing diseases including stroke, heart disease, lung cancer, chronic obstructive pulmonary diseases and respiratory infections, including pneumonia. Ambient air pollution alone caused some 4.2 million deaths in 2016, while household air pollution from cooking with polluting fuels and technologies caused an estimated 3.8 million deaths in the same period.

Table 1. EU (Convention) - Share of transport greenhouse gas emission

\begin{tabular}{|l|l|}
\hline Sector & Share \\
\hline Road transport & 72 \\
\hline Maritime & 13.6 \\
\hline Aviation & 13.3 \\
\hline Other Transportation & 0.5 \\
\hline Railways & 0.5 \\
\hline
\end{tabular}

More than $90 \%$ of air pollution-related deaths occur in low- and middle-income countries, mainly in Asia and Africa, followed by low- and middle-income countries of the Eastern Mediterranean region, Europe and the Americas.

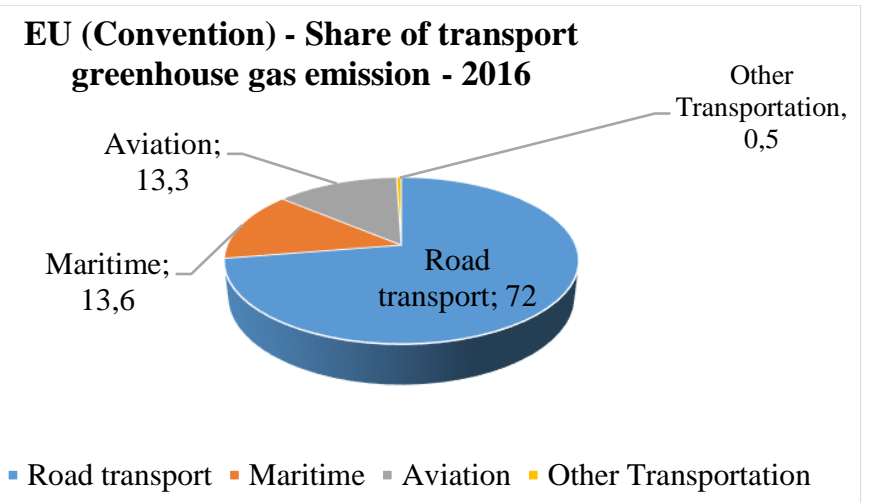

Figure 1. EU (Convention) — Share of transport greenhouse gas emission [14]

According the European Environment Agency [2], transport emissions by 2016 were 26.1 $\%$ higher relative to 1990. If preliminary data for 2017 is considered, they were $28 \%$ above 1990 levels. Road transport accounts for $82 \%$ of the transport greenhouse gas GHG emissions and one fifth of the EU's total GHG emissions and have grown since 
2014. The second and third Mobility Packages proposed by the Commission in November 2017 and May 2018 respectively include legislative initiatives on road transport vehicles and infrastructure. The initiatives focus on the reduction of GHG emissions and air pollutant emissions and aim for a broad take up of low-emission alternative fuels and lowemission vehicles on the market.

Since 2014, greenhouse gas emissions from the EU-28 transport sector (including international aviation but excluding international shipping) have been increasing. In comparison with 2015, emissions in 2016 had increased by almost $3 \%$, mainly on account of higher emissions from road transport, followed by aviation.

In 2016 [3], road transport was responsible for almost $72 \%$ of total greenhouse gas emissions from transport (including international aviation and international shipping). Of these emissions, $44 \%$ were contributed by passenger cars, while $19 \%$ came from heavyduty vehicles. In the same analyzed year (2016), transport (including aviation and shipping) contributed $27 \%$ of total greenhouse gas emissions in the EU-28. This figure drops to $20 \%$ if international shipping is excluded from the overall value. EEA estimates show that emissions from transport (including aviation) further increased by $1.5 \%$ in 2017.

Such alarming situations of environmental pollution by transport models, primarily automotive traffic, undoubtedly cause an appeal to the entire institutions in each country to find an appropriate mechanism for their reduction and putting them under control.

Due the need to foster a modified change in travel behavior, particularly in regard to encouraging the adoption of sustainable modes of transportation, this paper explores private transport behavior in understanding how users can be persuaded to adopt a more blended approach (i.e., integrating car, public transportation, and alternative modes on a daily basis) by favoring the social marketing model.

\section{SOCIAL MARKETING}

The concept Social marketing can be seen as an "American invention" in the $20^{\text {th }}$ century, because this concept-idea was initially formulated in the USA, exactly 50 years ago, since the publications of Kotler and Levy (1969) where in pioneering article "Broadening the Concept of Marketing", clearly proposed that as "a pervasive societal activity", marketing "goes considerably beyond the selling of toothpaste, soap, and steel", urging marketing researchers and practitioners to consider "whether traditional marketing principles are transferable to the marketing organizations, persons, and ideas"[4].

The term social marketing was formally introduced in 1971, when Kotler and Zaltman coin the term. In their article they defined social marketing as: the design, implementation, and control of programs calculated to influence the acceptability of social ideas and involving considerations of product planning, pricing, communication, distribution, and marketing research.

Over the years, the definitions of social marketing vary, but the essence of social marketing remain unchanged. Social marketing is a process that applies marketing principles and techniques to create, communicate, and deliver value in order to influence target audience behaviors that benefit society as well as the target audience.

According the Andresen [5] many believe that social marketing can have a major impact on society's myriad social problems. However, this impact can be seriously compromised if the technology is applied incorrectly or to areas in which is not appropriate. If practitioners misuse the concept, its effectiveness may be limited. If researchers and scholars assess its performance in areas for which it should not be responsible, social 
marketing may be blamed for failures for which it should not be held accountable. Andresen emphasis that the definition of social marketing would (1) keep practicing social marketers focused on the outcomes they are best suited to influence, (2) keep the discipline of social marketing distinguishable from its academic "competitors", and (3) keep social marketing programs out of area in which their likelihood of failure is high. He proposes the definition: Social marketing is the adaptation of commercial marketing technologies to programs designed to influence the voluntary behavior of target audience [6] as to improve their personal welfare and that of the society of which they are a part. The "bottom line" of social marketing campaign need to behavior change. Behaviorchange is the benchmark used to design and evaluate interventions.

Kotler and Lee (2008) emphasized "social marketing is about influencing behaviors": similar to commercial sector marketers who sell goods and services, social marketers are selling behaviors. As they elaborated, social marketers typically try to influence their target audience toward four behavior changes: (1) accept a new behavior (e.g., compositing food waste); (2) reject a potential undesirable behavior (e.g., starting smoking); (3) modify a current behavior (e.g., increasing physical activity from 3-5 days of the week), or (4) abandon an old undesirable one (e.g., talking on a cell phone while driving). [7]

Researching the social marketing literature, it's clear that social marketing focuses on changing behavior, which is often reached by marketing a facilitating product. Therefore, social marketing often needs to focus on two things, promoting behavioral change and promoting the facilitating product. Today, social marketing practice and successful social marketing campaigns can be found all over the world. Countries active in applying social marketing techniques to public health vary at the levels of economic and technological development and differ in social, cultural, and regulatory environment.

Table 2. Definition of Terms

\begin{tabular}{|c|c|}
\hline Marketing & $\begin{array}{l}\text { - Human activity directed at satisfying needs and wants through } \\
\text { exchange processes (Kotler 1980:10). }\end{array}$ \\
\hline Social & $\begin{array}{l}\text { - Marketing The application of commercial marketing technologies to } \\
\text { the analysis, planning, execution, and evaluation of programs designed } \\
\text { to influence the voluntary behavior of target audiences in order to } \\
\text { improve their personal welfare and that of their society (Andreasen } \\
\text { 1995:7). }\end{array}$ \\
\hline Green Marketing - & $\begin{array}{l}\text { The management process responsible for identifying, anticipating and } \\
\text { satisfying the requirements of consumers and society in a profitable and } \\
\text { sustainable way (Peattie 1992:11). }\end{array}$ \\
\hline Sustainable Marketing & $\begin{array}{l}\text { - efforts that are not only competitively sustainable but are also } \\
\text { Marketing ecologically sustainable (Sneth and Parvatiyar 1995:6). }\end{array}$ \\
\hline Environmental Marketing & $\begin{array}{l}\text { - activities that recognize environmental stewardship as a Marketing } \\
\text { business development responsibility and business growth opportunity } \\
\text { (Coddington 1993:58). }\end{array}$ \\
\hline
\end{tabular}

Source: [15]

Many marketing academics believe that the adoption of marketing theory in programs of social change can enhance the potential for success and, in many cases, is actually an integral part of their success. How can marketing theory therefore help foster a modified change in travel behavior, particularly in regard to encouraging the adoption of sustainable modes of transportation? Before one can consider the answer to this question, 
an understanding of where this area of research lies within the general field of academic marketing needs to be considered. Presently there is a plethora of marketing terms that could be used in reference to this notion of "social marketing" and its derivatives. Among the terms commonly used are ecological marketing, social marketing, sustainable marketing, environmental marketing, and green marketing. Definitions of each are listed in the Table 2. [8]

It's evident that the core of social marketing theory lies primarily with activity, problems, directly related to health and attempting to modify or alter people's behavior. The main question of social marketing is how private transportation users to be persuaded to consider alternative modes of travel in removing themselves from an existing habitual decision-making process? Or could social marketing programs support demand management policies to become more effective in reducing total vehicle travel or in other ways encouraging alternative modes to be considered?

Social marketing programs benefit either individuals or society. Social marketing programs are designed to promote best quality of life (environment, better physical and mental health, breast self-examination, dieting, the immunization of children etc.).

Recognition of the health impacts of transportation actions has led to an increasing interest in assimilating health into transportation planning. WHO recognized [9] the multidimensional nature of quality of life on its definitions: "WHO defines quality of life as individuals" perception of their position in life in the context of the culture and value systems in which they live and in relation to their goals, expectations, standards and concerns. It is a broad ranging concept affect in a complex way by the person's physical health, psychological state, level of independence, social relationships, personal beliefs and their relationship to salient features of their environment. WHO, 1997).

Social marketing activities are related with "pro-environmental behavior" of people. The "pro-environmental behavior" is the "behavior that consciously seeks to minimize the negative impact of one's actions on the natural and built world (e.g. minimize resource and energy consumption, use of non-toxic substances, reduce waste production)" [10]. Obviously, careful consideration of conditions that favor or restrain pro-environmental behavior in the environmental policy planning will help to close the existing value-action gap thus facilitating the process of shifting society towards more sustainable lifestyles. The success of a social marketing campaign utilizes various instruments, practices, communication and media formats. The communication formats consist mainly of advertising (including public service advertising, simply called PSA), public relations, special event (like public meeting and national exhibitions), sponsorships, and personal communication (including word of mouth, such as clinic counseling and family visits). Communication media include traditional media (such as newspapers, magazines, radio, television, cinemas, billboards, and transits), nontraditional media (e.g., computer desktop wallpaper, plastic cups, posters, T-shirts, bike lights etc.

\section{TRANSPORT INFLUENCE OF ENVIRONMENT AND PUBLIC HEALTH: THE CASE OF MACEDONIA}

Air pollution in the country is a cause of serious concern as the limit values set for protection of human health, especially for particulate matter, are exceeded significantly, primary in the urban and industrial areas. The situation is the worst in the biggest urban settlements such as Skopje and Tetovo, with the annual mean concentrations of $\mathrm{PM}_{10}$ exceeding the annual limit value $(40 \mu \mathrm{g} / \mathrm{m} 3)$. In the past few years Skopje and Tetovo have been declared among the most polluted cities in the world. Moreover, in terms of 
mean concentrations of both $\mathrm{PM}_{10}$ and $\mathrm{PM}_{2.5}$, the World Health Organization (WHO) Ambient Pollution Database [11] for 2018 ranks Skopje as Europe's most polluted capital city. Skopje, a city of more than half a million people, located in the centre of the Balkan peninsula in southern Europe has been listed by the WHO amongst the cities in Europe with the highest concentration of harmful fine particulate matter (PM) 2.5 in the air. The latest data released by the WHO in 2018 shows a PM 2.5 annual mean level of 40 micrograms per cubic metre in Skopje-four times the recommended levels of $10 \mu \mathrm{g} / \mathrm{m}^{3}$.

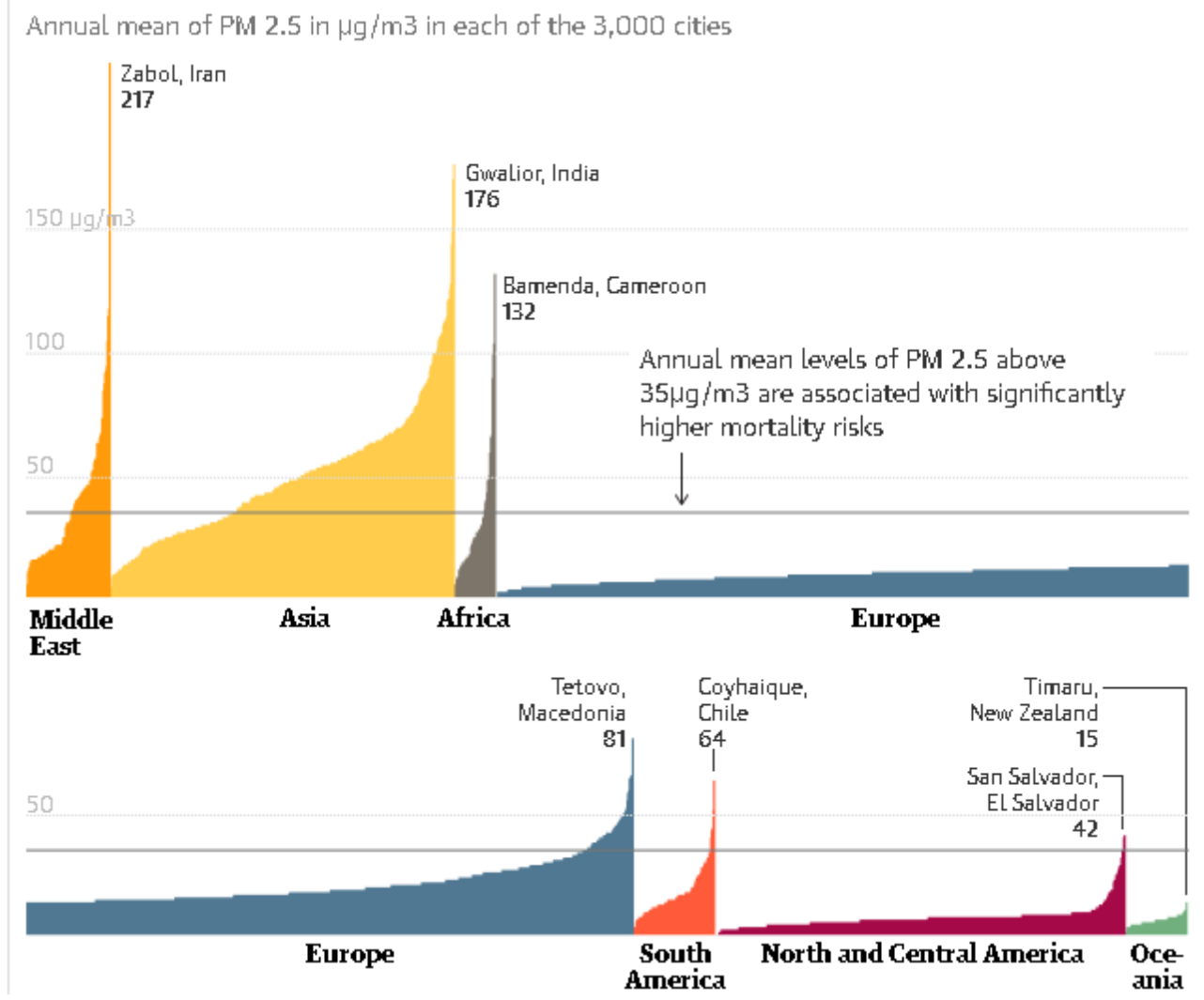

Figure 2. Annual mean of PM 2.5 in $\mu \mathrm{g} / \mathrm{m} 3$ [16]

Table 3. The most polluted cities in Macedonia - Annual mean of $\mathrm{PM}_{10}$ and $\mathrm{PM}_{2.5}$ in $\mu \mathrm{g} / \mathrm{m} 3$

\begin{tabular}{|c|c|c|c|c|c|c|}
\hline & & PN & & $\mathbf{P M}_{2.5}$ & & \\
\hline City/Town & Year & $\begin{array}{c}\text { Annual } \\
\text { mean, ug/m3 }\end{array}$ & $\begin{array}{l}\text { Temporal } \\
\text { coverage }\end{array}$ & $\begin{array}{c}\text { Annual mean, } \\
u g / \mathbf{m} 3\end{array}$ & $\begin{array}{l}\text { Temporal } \\
\text { coverage }\end{array}$ & $\begin{array}{l}\text { Number and type of } \\
\text { monitoring stations }\end{array}$ \\
\hline Bitola & 2016 & 53 & $>75 \%$ & (34)-converted value & NA & $\begin{array}{l}1 \text { Urban-Industrial, } \\
1 \text { Urban-Traffic }\end{array}$ \\
\hline Kavadarci & 2016 & 46 & $>75 \%$ & (29)-converted value & NA & 1 Urban-Industrial \\
\hline Kichevo & 2016 & 60 & $>75 \%$ & (38)-converted value & NA & 1 Urban-Industrial \\
\hline Kochani & 2016 & 44 & $>75 \%$ & (27)-converted value & NA & 1 Urban-Traffic \\
\hline Kumanovo & 2016 & 63 & $>75 \%$ & (40)-converted value & NA & 1 Urban-Background \\
\hline Lazaropole & 2014 & 16 & $>75 \%$ & (10)-converted value & NA & 1 Rural-Background \\
\hline Skopje & 2016 & 69 & $>75 \%$ & (40)-converted value & $>75 \%$ & $\begin{array}{l}1 \text { Urban-Background, } \\
1 \text { Urban-Industrial, } \\
2 \text { Urban-Traffic }\end{array}$ \\
\hline Tetove & 2016 & 97 & $>75 \%$ & (61)-converted value & NA & 1 Urban-Traffic \\
\hline Tetovo & 2013 & 140 & NA & (81)-converted value & NA & 1 station, traffic, urban \\
\hline Veles & 2016 & 41 & $>75 \%$ & (26)-converted value & NA & 1 Urban-Traffic \\
\hline
\end{tabular}

Source: [16]. 
Overall, Skopje as well as one of the most polluted cities, with poor air quality blamed for the premature death of 1,300 people each year. One of the serious reasons is a large number of vehicles (passenger cars, buses and freight vehicles), which appear as direct air pollutants. In particular, the situation deteriorates during the winter period of the year, during the heating season when other sources of pollution occur; in days of radiation fogs when the exhaust gases are kept in the city fog; during the early morning and afternoon hours when the highest frequency of traffic is performed, especially on the main roads; in those places in the cities where the transition from residential to industrial zones occurs, especially with the dynamics of walking and coming from work, etc.

Table 4. Air quality limit and target values for PM10 and PM2.5.

\begin{tabular}{|c|c|c|c|}
\hline Size fraction & A veraging period & Value & Comments \\
\hline $\mathrm{PM}_{10}$ limit value & One day & $50 \mu \mathrm{g} / \mathrm{m} 3$ & $\begin{array}{l}\text { Not to be exceeded more } \\
\text { than } 35 \text { days per year }\end{array}$ \\
\hline $\mathbf{P M}_{10}$ limit value & Calendar year & $40 \mu \mathrm{g} / \mathrm{m} 3$ & \\
\hline $\mathbf{P M}_{25}$ target value & Calendar year & $25 \mu \mathrm{g} / \mathrm{m} 3$ & \\
\hline $\mathbf{P M}_{25}$ limit value & Calendar year & $25 \mu \mathrm{g} / \mathrm{m} 3$ & $\begin{array}{l}\text { To be met by } 1 \text { January } \\
2020\end{array}$ \\
\hline $\mathbf{P M}_{25}$ limit value & Calendar year & $20 \mu \mathrm{g} / \mathrm{m} 3$ & $\begin{array}{l}\text { To be met by } 1 \text { January } \\
2025\end{array}$ \\
\hline $\begin{array}{l}\mathrm{PM}_{25} \text { exposure } \\
\text { concentration obligation }\end{array}$ & $\begin{array}{l}\text { Based on a three year } \\
\text { average }\end{array}$ & $20 \mu \mathrm{g} / \mathrm{m} 3$ & $\begin{array}{l}\text { To be met by } 1 \text { January } \\
2020\end{array}$ \\
\hline $\mathbf{P M}_{25}$ limit value* & & & To be met by 2025 \\
\hline \multicolumn{4}{|c|}{$\begin{array}{l}\text { Indicative limit value (Stage 2) to be reviewed by the Ministry of Environment and Physical Planning i } \\
2018 \text { in the light of further information on health and environmental effects, technical feasibility and } \\
\text { experience of the target value in EU Member States. } \\
\text { ** 0-20\% reduction in exposure (depending on the average exposure indicator in the reference year) } \\
\text { Source: Ministry of Environment and Physical Planning }\end{array}$} \\
\hline
\end{tabular}

In the Republic of Macedonia, the analyzes for the main polluters and climate change show that transport is one of the sectors where in the last years there is a growing trend of energy consumption. Namely, the share of transport in final energy consumption increased from $24 \%$ in 2012 to $32.5 \%$ in 2015 . Of the three subcategories (road, rail and air), the most dominant is road transport, with $97 \%$ participation. As a result, GHG emissions from this sector are also increasing, of which the most dominant (with almost $99 \%$ ) is $\mathrm{CO}_{2}$. In the total emissions at the national level, the transport sector increases its share of $10 \%$ in 2012 to $13 \%$ in 2014.

From the study conducted by the Research Center for Energy and Sustainable Development at the Macedonian Academy of Sciences and Arts, which is a whole with the Study on Heating in the City of Skopje, a policy analysis and measures (STUGRES), analyzing the ways in which they can be reduce greenhouse gas emissions and air pollution from heating in households in the City of Skopje. Additionally, this study is also a continuation of the Study on Transport Policy Analysis and Measures (STUTRA), which analyzes the mitigation of climate change from passenger cars at the national level (on the entire territory of the Republic of Macedonia).

Although transport mostly contributes to NOx emissions, the total measured NO2 concentrations in 2015 (from all sources) do not exceed the permissible limit values for the protection of human health. Nevertheless, it is necessary to go in the direction of changing the fleet by replacing the diesel vehicles (as the largest NOx emitters in transport) with hybrid or electric, which is proposed as a measure in this study. 
Using the results of the STUGRES study, a comparative analysis was made of how many emissions come from the transport, household and energy sectors. The results show that transport in 2015 in the city of Skopje participates with:

- $80 \%$ in NOx,

- $20 \%$ in CO, and

- $4 \%$ in PM2.5.

Before Euro passenger cars (whose number in 2016 is 9,122), they emit $874 \mathrm{t} \mathrm{CO}$. The following, Euro1 cars (17,246 vehicles), emit an additional $407 \mathrm{t} \mathrm{CO}$, or together, Euro and Euro1 (total of 26,368 cars) emit 1,281 t CO. In the figure, in the "cloud of exhausts", with the position of the center of the circle according to the y-axis, the number of cars of a certain emission standard (Euro) is given, and their $\mathrm{CO}$ emission with the number beside the circle and the size of the circle ). For example, Euro 2 cars in 2016 emit 353 t CO.

Approximately half of the passenger cars and buses still belong to the high-emission Euro 0 - Euro 2 classes whereas the share is less for light and heavy-duty vehicles. According to the vehicle register information there is still a quite considerable share (approximately $10-18 \%$ ) of the passenger cars, light duty vehicles and buses that belong to the oldest category of the cars (Euro 0) with no treatment systems for the exhaust gases. [12]

Unlike in most other European cities, the carbon monoxide limit value is still being exceeded in some Macedonian cities in several days per year. This is likely due to the old car fleet and the widespread use of wood for residential heating. Heavy traffic such as buses and trucks produce the largest amounts of emissions per vehicle. Diesel cars have higher NOx and particulate emissions compared to petrol cars with catalytic converters (Euro 1 onwards). Usually, when the vehicle gets older the emissions are increasing as the catalytic converter and other exhaust treatment systems lose some of the efficiency. The size of the particulates is very significant from the health point of view, as the finest particulates penetrate deeper in the human body causing more severe health impacts.

The emissions from road traffic affect the air pollution the most from the transport sector. The impact of road traffic emissions is the highest in urban areas with dense road networks and high volume of vehicles. The road traffic contributes to the nitrogen oxides, carbon monoxide, benzene and particulate, heavy metal and polycyclic aromatic hydrocarbon emissions. The emissions from road traffic depend on the type and age of the vehicles, mileage of each vehicle group and quality of the fuels used in the vehicles. Also driving cycle and speed have impact on the emissions; driving in the city area with low speed produces typically more emissions than smooth driving on the highway at a constant speed. In the European Union, the exhaust emission limit values of vehicles have been gradually tightened since 1992 with so called Euro class emission regulations. These continuously updated regulations from Euro 0 (no controls) to the current Euro 6 level have led to a significant reduction of the emissions produced by every new generation of vehicles.

Heavy traffic such as buses and trucks produce the largest amounts of emissions per vehicle. Diesel cars have higher NOx and particulate emissions compared to petrol cars with catalytic converters (Euro1 onwards). Usually, when the vehicle gets older the emissions are increasing as the catalytic converter and other exhaust treatment systems lose some of the efficiency. Based on the vehicle register information in year 2015, total amount of registered motor vehicles in the country was 436502.

\section{PUBLIC POLICIES AND PROGRAMS IN THE PROMOTION OF SUSTAINABLE TRANSPORT}


Urban air pollution continues to rise at an alarming rate, wreaking havoc on human health. It's dramatic, one of the biggest problems we are facing globally, with terrible future costs to society. The EU has been working for decades to improve air quality by controlling emissions of harmful substances into the atmosphere, improving fuel quality, and integrating environmental protection requirements into the transport, industrial and energy sectors. The Clean Air Programme for Europe (CAPE), published by the European Commission in late 2013 (European Commission, 2013), aims to ensure full compliance with existing legislation by 2020 at the latest, and to further improve Europe's air quality, so that by 2030 the number of premature deaths is reduced by half when compared with 2005. The most important measures that are expected to be implemented in the following period relate to the following activities [13]:

- The first pillar comprises ambient air quality standards set out in the Ambient Air Quality Directives (EU, 2004, 2008), requiring the Member States to adopt and implement air quality plans and meet standards in order to protect human health and the environment;

- The second pillar consists of national emission reduction targets established in the National Emission Ceilings (NEC) Directive (EU, 2016), requiring Member States to develop National Air Pollution Control Programmes by 2019 in order to comply with their emission reduction commitments;

- The third pillar comprises Emission and energy efficiency standards for key sources of air pollution, from vehicle emissions to products and industry. These standards are set out in EU legislation targeting industrial emissions, emissions from power plants, vehicles and transport fuels, as well as the energy performance of products and nonroad mobile machinery

In the planning of the city cores, a special place is dedicated to pedestrian zones, which will allow unhindered movement of pedestrians and cyclists in a space free of motor vehicles. Some cities have announced car-free or car-less visions, including Milan, Copenhagen, Madrid and Paris. Oslo plans to ban all cars from its city centre permanently by 2019. Chengdu in China is designing a new residential area in which people will be able to walk everywhere easily, reducing the need for cars. Pedestrian zones appear in all developed European cities in the last 30 years, driven by the need to create a space for pleasant movement and stay in urban centers. The content of the pedestrian zones should be fully adjusted to the people's residence, so in that space only the supplies of certain goods should be allowed in a certain part of the day, and the ambience itself should be enriched with many interesting contents such as greenery, benches, various cultural and convenient activities, etc. The main incentive for their arrangement is the increase of traffic jams in the cities with the insufficiently adapted road network with the increased traffic, which prevents the free movement of pedestrians and bringing them to danger of their lives. In the creation of transport policies in many countries, other instruments are also being promoted that do not affect people's environmental threats. For example, despite the increase in motorization, bicycles have continued to be used for personal mobility, and the volume and use of bicycle traffic is dependent on a country in the state. In fact, the bicycle is a component in national transport policy in several countries. Using the bicycle, especially for short trips, going to school, work or walks, is quite common. The share of state policy in several countries is growing in the construction, improvement, provision of separate paths, tunnels, bridges, and overpasses for cyclists, thus avoiding the collision between motor vehicles and cyclists. Car traffic with the accompanying dangers it brings with itself is more in many developed countries, for example in the 
Netherlands, with a series of state projects and legal measures endeavoring to put bicycle traffic as an alternative to traffic on motor vehicles. Despite the increased GDP, in many Western European cities, the use of the bicycle for short trips is quite current. For example, in Groningen, two-thirds of the population travel is not more than $5 \mathrm{~km}$ and $76 \%$ of the population are on foot or by bike. The Dutch policy is increasingly advocating the policy of using bicycles in internal traffic, increasing safety, protecting cyclists and improving the road infrastructure for this type of traffic.

\section{CONCLUSION}

Air pollution is a global threat leading to large impacts on health and ecosystems. Emissions and concentrations have increased in many areas worldwide. Air pollution is perceived as the second biggest environmental concern for Europeans after climate change and people expect the authorities to implement effective measures to reduce air pollution and its effects. Improving air quality remains a challenge for Europe also in the long-term. This requires a comprehensive approach across different sectors, from transport, energy, to local planning, bringing together all the different actors concerned. For its part the European Commission will continue to support Member States such as via the Clean Air Dialogues. Poor air quality reduces quality of life and is of great cost to the economy. There is no time to waste. Cost-effective solutions to improve air quality exist and are widely available. There is a need to act now to scale them up and implement them without delay across the EU to the benefit of the half a billion European citizens.

Social marketing activities are related with "pro-environmental behavior" of people. The "pro-environmental behavior" is the "behavior that consciously seeks to minimize the negative impact of one's actions on the natural and built world (e.g. minimize resource and energy consumption, use of non-toxic substances, reduce waste production)". Today, social marketing practice and successful social marketing campaigns can be found all over the world. Countries active in applying social marketing techniques to public health vary at the levels of economic and technological development and differ in social, cultural, and regulatory environment.

Social marketing programs benefit either individuals or society. Social marketing programs are designed to promote best quality of life (environment, better physical and mental health, breast self-examination, dieting, the immunization of children etc.). It's evident that the core of social marketing theory lies primarily with activity, problems, directly related to health and attempting to modify or alter people's behavior.

Effective action to reduce air pollution and its impacts requires a good understanding of its causes, how pollutants are transported and transformed in the atmosphere, how the chemical composition of the atmosphere changes over time, and how pollutants impact humans, ecosystems, the climate and subsequently society and the economy. To curb air pollution, collaboration and coordinated action at international, national and local levels must be maintained, in coordination with other environmental, climate and sectoral policies. Holistic solutions involving technological development, structural changes and behavioral changes are also needed, together with an integrated multidisciplinary approach. 


\section{REFERENCES}

[1] Climate \& clean air coalition to reduce short-lived climate pollutants:

http://www.ccacoalition.org/en/news/world-health-organization-releases-new-global-airpollution-data [13.12.2018]

[2] European Environment Agency (2016): Transport and Environment Reporting Mechanism (TERM). p.2. https://www.eea.europa.eu/ [14.12.2018]

[3] National emissions reported to the UNFCCC and to the EU Greenhouse Gas Monitoring Mechanism provided by European Environment Agency (EEA)

https://www.eea.europa.eu/data-and-maps/data/national-emissions-reported-to-the-unfccc-andto-the-eu-greenhouse-gas-monitoring-mechanism-14

[4] Cheng H., Kotler P., Lee R. N. (2011): Social marketing for public health: Global trends and success stories. Jones and Bartlett Publishers, LLC. 2011.p.2.

[5] Andreasen A.: Social Marketing: Its Definition and Domain. Journal of Public Policy \& Marketing. Spring 1994, Vol.13 (1), 1994.p.108

[6] Andreasen A.: Marketing social marketing in the social change marketplace. Journal of Public Policy \&Marketing. Vol.21(1) Spring 2010, p.7.

[7] Cheng H., Kotler P., Lee R. N. (2011): Social marketing for public health: Global trends and success stories. Jones and Bartlett Publishers, LLC. 2011.p.3.

[8] McGovern E.: Social Marketing Applications and Transportation Demand Management: An Information Instrument for the 21st Century. Management. Journal of Public Transportation, Vol. 8, No. 5, 2005 . p.6.

[9] Lee J.R., Sener N.I.: Transportation planning and quality of life: Where do they intersect? Elsevier. Transport policy 48(2016) 146.

[10] Kollmuss, A. and Agyeman, J. (2002). Mind the Gap: why do people act environmentally and what are the barriers to pro-environmental behavior? Environmental Education Research, 8(3), 239-260.

[11] WHO: Global urban ambient air pollution database

https://www.who.int/phe/health_topics/outdoorair/databases/cities/en/

[12] Ministry of environment and physical planning (2017): Macedonian air quality assessment report for the period 2005-2015. Skopje: Ministry of environment and physical planning,. 2017. p.16.

[13] European commission, communication from the commission to the European parliament, the council, the European economic and social committee and the committee of the regions: a Europe that protects: Clean air for all. Brussels 17.5.2018 $\operatorname{COM}(2018)$ 330. p.2.

[14] National emissions reported to the UNFCCC and to the EU Greenhouse Gas Monitoring Mechanism provided by European Environment Agency (EEA)

https://www.eea.europa.eu/data-and-maps/data/national-emissions-reported-to-the-unfccc-andto-the-eu-greenhouse-gas-monitoring-mechanism-14

[15] McGovern E.: Social Marketing Applications and Transportation Demand Management: An Information Instrument for the 21st Century. Management. Journal of Public Transportation, Vol. 8, No. 5, 2005 . p.6.

[16] Ambient Air Quality Database, WHO, 2018.

https://www.theguardian.com/environment/2016/may/12/air-pollution-rising-at-an-alarmingrate-in-worlds-cities 